\title{
Rapeseed oil and magnesium manipulations affect the seizure threshold to kainate in mice*
}

\author{
Nicole PAGÈS ${ }^{1,2}$ \\ Pierre MAUROIS ${ }^{3}$ \\ Pierre $\mathrm{BAC}^{3}$ \\ Joseph VAMECQ ${ }^{4}$ \\ 1 NMPA, \\ CNPS, \\ Paris XI University, \\ Orsay, \\ France \\ $<$ nicole.pages4@hotmail.fr $>$ \\ ${ }^{2}$ Toxicology, \\ Pharmacy, \\ Strasbourg University, \\ IIlkirch, \\ France \\ ${ }^{3}$ Neuropharmacology, \\ Faculty of Pharmacy, \\ Châtenay-Malabry, \\ France \\ ${ }^{4}$ Inserm \& Center of Biology and \\ Pathology, \\ CHRU Lille, \\ France
}

Magnesium deprivation is long known to cause brain vulnerability to inflammatory, oxidative and convulsant injuries. In mice, this particular nutritional animal model may be exploited for its susceptibility to audiogenic seizures to evaluate in vivo brain activity of anticonvulsant, neuroprotective, and antiinflammatory/antioxidant compounds (Bac et al., 1998; Vamecq et al., 2003; Maurois et al., 2008; Maurois et al., 2009; Pagès et al., 2010; Vamecq et al.,

"Lecture from the symposium "Lipids and Brain II" held by The French Society for the Study of Lipids (Sfel) - Paris 2830 March 2011, cf. OCL 18-4 and 18-5.

\begin{abstract}
We have previously shown that the drop in N-methyl-D-aspartate (NMDA)induced seizure threshold caused by nutritional magnesium deprivation responded well to the $w$-3 polyunsaturated fatty acid (PUFA) alpha-linolenate (ALA) (5\% rapeseed oil) diet when compared to w-6 PUFA diet. In the present work, kainate-induced seizures are shown to be also exacerbated by magnesium deprivation. ALA diet better attenuates this seizure exacerbation when compared to the non-ALA diet. The reversion of the drop in kainate seizure threshold induced in these conditions by magnesium administration was, however, better under the non-ALA diet in comparison with the ALA diet. Taken as a whole, present data indicate that kainate like NMDA brain injury is attenuated by ALA diet. On the other hand, the relative failure of ALA diet to potentiate reversion induced by magnesium might suggest that magnesium and ALA protections are not additive.
\end{abstract}

Key words: rapeseed oil, corn: sunflower oil, omega-3, alphalinolenic acid, magnesium deficiency, kainate receptor, magnesium chloride hexahydrate, kainate-induced seizure, seizure threshold

2010; Pagès et al., 2011). Chronic magnesium deprivation based on a vegetable oil diet devoided of $\varpi-3$ polyunsaturated fatty acids ( $\varpi 3$ PUFA) (diet containing 5\% corn/sunflower oil) in mice was also recently shown to represent an interesting nutritional model for in vivo exacerbated NMDA receptor function (reduction of NMDA seizures threshold) which responds remarkably to acute magnesium supply, adding experimental evidence that magnesium administration is a promising approach of glutamate-mediated brain disorders (Maurois et al., 2009).

PUFAs are essential components of the central nervous system (CNS) and are brought exclusively by food (Rapoport et al., 2007). Many recent studies have documented the beneficial effects of ఐ-3 PUFA on cardiovascular diseases (Heurteaux et al., 2006) and neurological disorders (Vreugdenhil et al., 1996; Xiao and Li, 1999; Lauritzen et al., 2000; Kim et al., 2001; Blondeau et al., 2009; Delattre et al., 2010) including epilepsy (Heurteaux et al., 2006; Pagès et al., 2011). These studies mainly focused on beneficial effects of docosahexaenoic acid (DHA) and eicosapentaenoic (EPA) acids, and to a less extent on the effects of alpha-linolenic acid (ALA) (18:3 n-3). ALA is supplied with diet via different vegetal origins: it represents $9 \%$ of the rapeseed oil composition, which also contains $60 \%$ monounsaturated fatty acids (MUFA) (18:1 fatty acid) and 20\% ఐ6PUFA. Its $\varpi 6 / \varpi 3$ ratio is low (close to 3 ) contrasting with the high ratio (more than 80 ) characterizing corn:sunflower oils which contain 28\% MUFA, 56\% ఐ-6 PUFA and $0.6 \% \varpi-3$ PUFA (Pagès et al., 2011). Diet containing $5 \%$ rapeseed oil (rich in ఐ-3 alpha-linolenate (ALA) improves protection against experimental seizures including NMDA induced seizures to a higher extent than diet containing 5\% corn/sunflower oil devoided of $\varpi$ - 3 PUFA (Pagès et al., 2011), supporting modulation of glutamate neurotransmission by ळ-3 PUFAs. Glutamate-driven excitatory synaptic neurotransmission in the mammalian central nervous system is also mediated in major part by receptors other than the NMDA-type receptor and

To cite this article: Pagès $N$, Maurois $P, B a c P$, Vamecq J. Rapeseed oil and magnesium manipulations affect the seizure threshold to kainate in mice. OCL 2011; 18(6): 314-316. doi : 10.1684/ocl.2011.0414 
including those coupled to channels highly permeable to $\mathrm{Na}^{+}$and $\mathrm{K}^{+}$and less permeable to $\mathrm{Ca}^{2+}$ ions (Hatt et al., 1988; Colquhoun et al., 1992). When activated, the non-NMDA glutamate receptorchannels are typically associated with inward $\mathrm{Na}^{+}$current, these channels being classified into kainate- and $\alpha$-amino- 3 hydroxy-5-methylisoxazole (AMPA)- preferring types (Collingridge and Ras, 1989; Monaghan et al., 1989; Lodge, 1997).

The aim of the present study was to study whether dietary rapeseed oil could also protect mice against kainate-induced seizures in adult mice fed magnesium deficient (35 ppm) or normal magnesium containing (900 ppm) diets containing 5\% lipids brought by either corn: sunflower oil or rapeseed oil.

\section{Materials and methods}

The investigation was conforming to the Guide for the Care and Use of Laboratory Animals published by the US National Institute of Health (NIH, No 85-23, revised 1996). Female Swiss OF1 mice, were purchased from Janvier (Le Genest-St-Isle, France) and divided into 3 groups $(n=20)$.

The control group was fed a diet containing normal magnesium levels $(\geq 900$ \pm 50 ppm) (control Mg+diets) under the form of industrial pellets containing soya lipids (UAR, France)

The two magnesium-deficient groups received different diets (magnesiumdeficient (Mg-) diets). These diets impoverished in magnesium were designed by restricting severely the magnesium content to $35 \pm 5 \mathrm{ppm}$ as described previously (Maurois et al., 1989; Maurois et al., 2009) and differed in fat content: ALA-poor (a mix of corn and sunflower oils (3:1)) or ALA-rich (pure rapeseed oil).
Mice were placed eight per cage and maintained on a 12:12 h light-dark schedule at $21 \pm 1{ }^{\circ} \mathrm{C}$. They had free access to food and to distilled water which avoids additional magnesium input. In current practice, in order to prevent food oxidation, fresh diets were lyophilized and frozen at $-20{ }^{\circ} \mathrm{C}$. They were given to mice every day in sufficient amount.

At the end of the magnesium deprivation period (30 days), kainate seizure tests were performed by evaluating the capacity of the various diets to provide protection against threshold seizures through determination of the lethal dose $100\left(\mathrm{LD}_{100}\right.$, minimal dose inducing death of $100 \%$ tested animals). The reversion of susceptibility to kainate seizures was studied for intraperitoneal administration of magnesium chloride hexahydrate (dissolved in a $0.9 \%$ saline water solution) performed 30 min before kainate administration. The daily amount of magnesium delivered to mice by a deficient diet corresponded to grosso modo $5.6 \mathrm{mg}$ magnesium/kg body weight. This daily amount, or several-fold this amount, was given intraperitoneally to mice acutely in the form of magnesium chloride hexahydrate, $46.8 \mathrm{mg}$ of which contained $5.6 \mathrm{mg}$ magnesium).

Statistical analysis: Data were expressed as mean \pm SEM and analyzed by Student's t-test.

\section{Results}

Threshold to kainate-induced seizures in mice fed a normal magnesium diet was found to be $45 \mathrm{mg} / \mathrm{kg}$. In magnesiumdeprived mice, kainate seizure threshold was significantly $(p<0.05)$ lowered to 32 and $39 \%$ of these values in groups fed diets containing corn: sunflower (ALA poor) and rapeseed (ALA rich) oils, respectively. Thresholds in these two respective groups were significantly $(p<0.05)$ different 14.5 and $17.5 \mathrm{mg} / \mathrm{kg}$ (table 1).

The drop induced by magnesium deficiency in the threshold to kainateinduced seizures was partly reversed by acute intraperitoneal administrations of $28 \mathrm{mg} / \mathrm{kg}$ magnesium which increased by 213 and $154 \%$ the kainate seizure threshold of mice given a magnesiumdeficient diet supplemented with corn: sunflower (ALA poor) and rapeseed (ALA rich) oils, respectively (table $1, \mathrm{p}<0.05$ ). The threshold was re-heightened significantly $(p<0.05)$ to 31 and to $27 \mathrm{mg}$ kainate/kg, under corn: sunflower (ALA poor) and rapeseed (ALA rich) oils, respectively. However, the levels did not reach the initial values observed with normal magnesium diet (only $60 \%$ of $\mathrm{Mg}+$ diet).

Increasing the doses of acute magnesium administration did not induce substantial gain in further reversing these thresholds, magnesium doses superior to $30 \mathrm{mg} / \mathrm{kg}$ body weight (from 30 to $40 \mathrm{mg} / \mathrm{kg}$ ) in the form of chloride salt becoming progressively toxic and finally lethal for the magnesium-deficient animals (data not shown).

\section{Discussion}

In the wake of previous studies, the present work originally highlights a lowering of threshold to kainate seizures in OF1 mice induced by chronic exposition to nutritional deprivation in magnesium. The shift observed in this threshold was operated from $45 \mathrm{mg} / \mathrm{kg}$ (normal magnesium fed animals) to 14.5 and to $17.5 \mathrm{mg} / \mathrm{kg}$ in mice given a magnesiumdeficient diet based on corn: sunflower (ALA-poor diet) or rapeseed oils (ALA-rich

Table 1. Effects magnesium-deficient diets on threshold to kainate-induced seizures

\begin{tabular}{|c|c|c|c|}
\hline Diets & & $\begin{array}{l}\text { Threshold to kainate-induced } \\
\text { seizures }(\mathrm{mg} / \mathbf{k g})\end{array}$ & $\begin{array}{l}\text { Threshold to kainate-induced } \\
\text { seizure after acute } \mathrm{MgCl}_{2} \\
\text { injection }(\mathbf{m g} / \mathbf{k g})\end{array}$ \\
\hline $\mathrm{Mg}+$ & Commercial diet & $\begin{array}{l}45.0 \pm 2.2^{* a} \\
\text { (reference threshold) }\end{array}$ & \\
\hline \multirow[t]{2}{*}{ Mg- } & ALA poor diet (corn/sunflower) & $14.5 \pm 3.1^{*^{b}}$ & $31.0 \pm 2.0^{*^{d}}$ \\
\hline & ALA rich diet (rapeseed) & $17.5 \pm 1.6^{\star c}$ & $27.2 \pm 1.5^{\star \mathrm{d}}$ \\
\hline
\end{tabular}

Evaluations were performed on 10 mice in each experimental group and condition. Mg+, normal magnesium-containing diet; Mg-, magnesiumdeficient diets; ALA, alpha-linolenic acid. ${ }^{*}, \mathrm{p}<0.05$;

$\star a, * b, * c$, groups significantly different $p<0.05 ;{ }^{* d}$ groups acutely injected versus corresponding non injected groups significantly different $p<0.05$ 
diet), respectively. Partial reversions (213 and 154\% under corn: sunflower and rapeseed oils, respectively) in magnesium deficiency-driven drop of kainate seizure threshold were provided by acute intraperitoneal administration of magnesium chloride hexahydrate. In the present series of experiments, previously reported abilities of acute magnesium administration and of rapeseed oil-based magnesium-deficient diet to protect fully and partly, respectively, mice against audiogenic seizures were again observed. The main contribution of this study is the evidence of a better ability of $\varpi 3 P U F A-$ rich oil (vs $\varpi 3$ PUFA-poor oil) to protect brain against the drop induced by magnesium deficiency in kainate seizure threshold. The fact that, paradoxically, rapeseed oils (ALA-rich diet) vs corn: sunflower (ALA-poor diet) offer to magnesium administration a lower capacity to reverse this drop might further suggest that magnesium and $\varpi 3$ PUFA-mediated brain protective mechanisms are not additive. Elucidation of these emerging and intriguing issues is in progress.

\section{REFERENCES}

Bac P, Maurois P, Dupont C, et al. Magnesiumdeficiency-dependent audiogenic seizures (MDDASs) in adult mice: a nutritional model for discriminatory screening of anticonvulsant drugs and original assessment of neuroprotection properties. / Neurosci 1998; 18: 4363-73.

Blondeau N, Nguemeni C, Debruyne DN, et al. Subchronic alpha-linolenic acid treatment enhances brain plasticity and exerts an antidepressant effect: a versatile potential therapy for stroke, Neuropsychopharmacology 2009; 34: 2548-59.

Collingridge $\mathrm{Gl}$, Ras L. Excitatory amino acid receptors in the vertebrate central nervous system. Pharmacol Rev 1989; 40: 145-95.
Colquhoun D, Jonas P, Sakmann B. Action of brief pulses of glutamate on AMPA/kainate receptors in patches from different neurones of rat hippocampal slices. J Physiology 1992; 458: 261-87.

Delattre Am, Kiss A, Szawka Re, et al. Evaluation of chronic omega-3 fatty acids supplementation on behavioral and neurochemical alterations in 6-hydroxydopaminelesion model of Parkinson's disease. Neurosci Res 2010; 66: 256-64.

Hatt $\mathrm{H}$, Franke C, Dudel J. Ionic permeabilities of L-glutamate activated, excitatory synaptic channel in crayfish muscle. Pflügers Archiv 1988; 411: 8-16.

Heurteaux C, Laigle C, Blondeau N, Jarretou G, Lazdunski M. Alpha linolenic acid and riluzole treatment confer cerebral protection and improve survival after focal brain ischemia. Neuroscience 2006; 137: 241-51.

Kim HY, Akbar M, Kim KY. Inhibition of neuronal apoptosis by polyunsaturated fatty acids. I Mol Neurosci 2001; 16: 223-7.

Lauritzen I, Blondeau N, Heurteaux, C Widmann C, Romey G, Lazdunski M. Polyunsaturated fatty acids are potent neuroprotectors. EMBO / 2000; 19: 1784-93.

Lodge D. Subtypes of glutamate receptors: historical perspectives on their pharmacological differentiation. In: Monaghan DT, Wentholdm RJ, Eds. The lonotropic Glutamate Receptors. Totowa (NJ, USA): Humana Press, 1997.

Maurois P, Gueux E, Rayssiguier Y. Protective effect of severe magnesium deficiency on Plasmodium chabaudi infection. Magnes Res 1989; 2: 183-7.

Maurois $P$, Pagès $N, B a c P$, et al. Threshold to NMDA-induced seizures in mice undergoing chronic nutritional magnesium deprivation is lowered in a way partly responsive to acute magnesium and antioxidant administrations. Brit J Nutr 2009; 101: 317-21.

Maurois $\mathrm{P}$, Rocchi S, Pagès $\mathrm{N}$, et al. The PPAR gamma-agonist FMOC-L-Leucine protects both mature and immature brain. Biomed Pharmacother 2008; 62: 259-63.

Monaghan D, Bridges R, Cotman C. The excitatory amino acid receptors: their classes, pharmacology and distinct properties in the function of the central nervous system. Ann Rev Pharmacol Toxicol 1989; 29: 314-20.

Pagès $N$, Maurois $P$, Delplanque $B$, et al. Activities of $\alpha$-asarone in various animal seizure models and in biochemical assays might be essentially accounted for by antioxidant properties. Neurosci Res 2010; 68: 337-44.

Pagès $N$, Maurois $P$, Delplanque $B$, et al. Brain protection by rapeseed oil in magnesiumdeficient mice. Prostaglandins Leukot Essent Fatty Acids 2011; 85: 53-60.

Rapoport SI, Rao JS, Igarashi M. Brain metabolism of nutritionally polyunsaturated fatty acids depends on both the diet and the liver. Prostaglandins Leukot Essent Fatty Acids 2007; 77: 251-61.

Vamecq J, Maurois P, Bac P, et al. Potent mammalian cerebroprotection and neuronal cell death inhibition are afforded by a synthetic antioxidant analogue of marine invertebrate cell protectant ovothiols. Eur J Neurosci 2003; 18: 1110-20.

Vamecq J, Maurois $P$, Pagès $N$, et al. 1,2ethane bis-1-amino-4-benzamidine is active against several brain insult and seizure challenges through anti-NMDA mechanisms targeting the $3 \mathrm{H}-\mathrm{TCP}$ binding site and antioxidant action. Eur J Med Chem 2010; 45: 3101-10.

Vreugdenhil M, Bruehl C, Voskuyl RA, Kang JX, Leaf A, Wadman WJ. Polyunsaturated acids modulate sodium and calcium currents in CA1 neurons. Proc Nat Acad Sci USA 1996; 93: 12559-63.

Xiao YF, Li X. Polyunsaturated fatty acids modify mouse hippocampal neuronal hyperexcitability during excitotoxic or convulsant stimulation. Brain Res 1999; 846: 112-21. 